Supporting Information

\title{
High-Performance Blue-Excitable Yellow Phosphor Obtained from an Activated Solvochromic Bismuth-Fluorophore Metal-Organic Framework
}

\footnotetext{
Benjamin J. Deibert, ${ }^{\dagger, \phi}$, Ever Velasco, ${ }^{\dagger, \phi}$ Wei Liu, ${ }^{\dagger}$ Simon J. Teat, ${ }^{\S}$ William P. Lustig, ${ }^{\dagger}$ Jing $\mathrm{Li}^{\dagger, *}$

${ }^{\dagger}$ Department of Chemistry and Chemical Biology, Rutgers, The State University of New Jersey, Piscataway, New Jersey 08854, United States

${ }^{\S}$ Advanced Light Source, Lawrence Berkeley National Laboratory, Berkeley, California 94720, United States
} 


\section{Contents:}

S1: Chemicals and Instrumentation.................................................. 2

S2: Synthetic Procedures............................................................... $3-4$

S3: Single Crystal X-ray Crystallography (Table S1) ............................... 5

S4: Structure Plots and Polyhedral Net Depictions (Figures S1 and S2) ................... 6-7

S5: Activation Procedure and Solvochromic Studies for the Transformation of $\mathbf{1}$ to $\mathbf{1 A}$ and PC-WLED Coating .................................................................... 8

S6: Thermogravimetric Analysis (Figures S3 and S4)............................... 9-10

S7: Powder X-ray Diffraction (Figures S5 and S6) ................................... 11-12

S8: UV-Vis Spectroscopy (Figure S7) .......................................... 13

S9: Photoluminescence Spectroscopy (Figure S8) ................................... 14

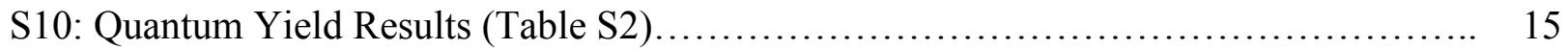

S11: Comparison of Blue-Excitable Yellow Phosphors (Table S3)...................... 15

S12: References.................................................................... 16 


\section{S1: Chemicals and Instrumentation}

Unless otherwise stated, all starting chemicals used in this study were reagent grade (>97\%) and purchased from commercial sources. Except for benzoic acid, chemicals were used as received without further purification. Benzoic acid was recrystallized in a hot 1:1 mixture of ethanol (EtOH) and deionized (DI) water.

\section{Single Crystal X-ray Diffraction (SXRD) and Powder X-ray Diffraction (PXRD)}

Single crystal diffraction data for $\mathbf{1}$ was collected at $100 \mathrm{~K}$ on a Bruker APEXII CCD diffractometer using the synchrotron source $(\lambda=0.77490 \AA)$ at the Advanced Light Source 11.3.1 Chemical Crystallography beamline. The refinement method used was full-matrix leastsquares on $\mathrm{F}^{2}$. PXRD patterns were recorded on a Rigaku Ultima IV X-ray diffractometer with $\mathrm{Cu} \mathrm{K} \alpha$ radiation $(\lambda=1.5406 \AA)$. A graphite monochromator was used and the generator power settings were set to $40 \mathrm{kV}$ and $44 \mathrm{~mA}$. Data were collected between $3-35^{\circ} 2 \theta$ with a step size of $0.02^{\circ}$ and a scan speed of $1.5 \mathrm{deg} / \mathrm{min}$.

\section{Thermogravimetric Analysis (TGA)}

Measurements were performed using a TA Q5000 Thermogravimetric Analyzer with a temperature ramp of $10{ }^{\circ} \mathrm{C} / \mathrm{min}$ from room temperature to $600{ }^{\circ} \mathrm{C}$ under nitrogen gas flow $(20$ $\mathrm{mL} / \mathrm{min}$ ). For sample activation, the isotherm setting of the TGA was used to hold the sample at a specified temperature for set durations under nitrogen flow.

\section{Ultraviolet-visible (UV-Vis) Spectroscopy}

The optical absorption spectra of solid samples were collected on a Shimadzu UV-3600 spectrophotometer at room temperature. The baseline was taken on a $\mathrm{BaSO}_{4}$ standard. Samples were prepared on a quartz sample holder and diffuse reflectance measurements were converted to absorption using the Kubelka-Munk Function.

\section{Photoluminescence (PL) Spectroscopy}

PL excitation and emission spectra were measured on a Varian Cary Eclipse spectrophotometer at room temperature. A quartz slide was used as the sample holder. Emission spectra were first collected using an excitation wavelength of $360 \mathrm{~nm}$. The emission maximum was set as the monitored emission wavelength for the corresponding excitation spectra.

\section{Internal Quantum Yield (QY) Measurements}

The fluorescence internal quantum yields were measured on a Hamamatsu C9220-03 system with a $150 \mathrm{~W}$ xenon monchromatic lamp and an integrating sphere. Sodium salicylate (60\% QY) and yttrium aluminum garnet doped with cerium (YAG:Ce $\left.\mathrm{Ce}^{3+}, 95 \% \mathrm{QY}\right)$ were used as standards at 360 and $455 \mathrm{~nm}$ wavelengths, respectively. 


\section{S2: Synthetic Procedures}

\section{H4tcbpe}

The 4',4"',4"'",4"'"'"-(ethene-1,1,2,2-tetrayl)tetrakis(([1,1'-biphenyl]-4-carboxylic acid)) (H4tcbpe) ligand was prepared using the reported method with slight modifications, as briefly outlined below. ${ }^{1}$

Preparation of tetra-(4-bromo-phenyl)ethylene (tpe-Br)

Tetraphenylethylene (tpe, $\sim 6.0 \mathrm{~g}$ ) was stored on a watch glass in a small glass desiccator over liquid $\mathrm{Br}_{2}$ for one week (in a fume hood, liquid $\mathrm{Br}_{2}$ is particularly reactive and corrosive) with occasional careful mixing of the tpe powder and adding additional $\mathrm{Br}_{2}$ if necessary. The crude orange product was recrystallized by dissolving in dichloromethane (DCM), precipitating out with methanol $(\mathrm{MeOH})$, and filtering and washing with $\mathrm{MeOH}$.

\section{Suzuki coupling between tpe-Br and 4-(methoxycarbonyl)phenylboronic acid}

$90 \mathrm{~mL}$ of tetrahydrofuran (THF) and $15 \mathrm{~mL}$ of $3 \mathrm{M}$ aqueous $\mathrm{K}_{2} \mathrm{CO}_{3}$ were charged to a three neck round bottom flask. $2.85 \mathrm{~g}(4.4 \mathrm{mmol})$ of the- $\mathrm{Br}$ and $5.00 \mathrm{~g}(27.8 \mathrm{mmol})$ of 4(methoxycarbonyl)phenylboronic acid were added to the flask along with a condensing column and rubber septum, and was nitrogen purged multiple times. $0.20 \mathrm{~g}(0.2 \mathrm{mmol})$ of $\mathrm{Pd}\left(\mathrm{Ph}_{3}\right)_{4}$ was weighed in a glove box and stored in a vial with a septum under inert atmosphere. 10-15 mL of THF was used to dissolve the Pd catalyst, which was then injected to the purged reactor through the rubber septum and refluxed at $90{ }^{\circ} \mathrm{C}$ for 3 days with constant stirring (Note: $\mathrm{Pd}\left(\mathrm{Ph}_{3}\right)_{4}$ is very air sensitive). After cooling to room temperature, the crude ester product was extracted with DCM a minimum of three times, washed with water, dried over anhydrous magnesium sulfate and rotovapped to dryness. The crude product was then purified via flash chromatography using a 1:29 mixture of ethyl acetate:DCM as the mobile phase. The obtained purified ester is a greenyellow solid.

\section{Base hydrolysis and acidification of the tcbpe-ester to form $\mathrm{H}_{4}$ tcbpe}

$2.43 \mathrm{~g}(2.8 \mathrm{mmol})$ of the tcbpe ester was dissolved in $30 \mathrm{~mL}$ of THF in a round bottom flask; 30 $\mathrm{mL}$ of $\mathrm{KOH}(3 \mathrm{M})$ was then added and heated to reflux $\left(90{ }^{\circ} \mathrm{C}\right)$ with vigorous mixing. After a minimum of 6 hours of reflux, the reaction was cooled to room temperature and concentrated via rotary evaporation to remove organic solvent. The remaining reaction slurry was added dropwise to $6 \mathrm{M} \mathrm{HCl}$, resulting in precipitation of the carboxylic acid which was then filtered and washed with DI water until $\mathrm{pH}$ neutral and dried under vacuum. The final product was confirmed by NMR. Note: if $\mathrm{HCl}$ was added to the reaction slurry for the acid workup, often the ligand will crash out of solution as the potassium salt form, which is a white powder with blue PL emission. Adding the slurry to an acid solution prevents this from occurring. 


\section{$\mathrm{Bi}_{4} \mathrm{O}_{2}(\mathrm{Hsal}) \cdot \mathbf{2} \cdot \mathbf{M e C N}$}

The tetranuclear bismuth cluster $\mathrm{Bi}_{4} \mathrm{O}_{2}(\mathrm{Hsal})_{8} \cdot 2 \mathrm{MeCN}\left(\mathrm{H}_{2} \mathrm{sal}=\right.$ salicylic acid $)$ was prepared at room temperature following the reported conditions. ${ }^{2} 0.11 \mathrm{~g}(0.25 \mathrm{mmol})$ of triphenyl bismuth and $0.10 \mathrm{~g}(0.75 \mathrm{mmol})$ of salicylic acid were added to a $20 \mathrm{~mL}$ scintillation vial and dissolved in $1.4 \mathrm{~mL}$ of acetonitrile $(\mathrm{MeCN})$ with sonication. The solution was then left undisturbed for a few days while crystal clusters of the product formed. The reaction supernatant was decanted and the crystalline product was washed with toluene (3x). Phase purity was confirmed via PXRD.

\section{$\left.[\text { BiK(tcbpe)(DMF) })_{2}\right] \cdot x$ DMF (1)}

Single crystals of the new LMOF suitable for diffraction studies were obtained solvothermally. $\mathrm{Bi}_{4} \mathrm{O}_{2}(\mathrm{Hsal})_{8} \cdot 2 \mathrm{MeCN}(10.0 \mathrm{mg}, 0.005 \mathrm{mmol}), \mathrm{H}_{4}$ tcbpe $(20.0 \mathrm{mg}, 0.025 \mathrm{mmol}), \mathrm{KCl}(3.0 \mathrm{mg}$, $0.040 \mathrm{mmol})$ and benzoic acid $(200 \mathrm{mg}, 1.64 \mathrm{mmol})$ were added to a $20 \mathrm{~mL}$ scintillation vial with $2 \mathrm{~mL}$ of DMF and sonicated for 2 mins. The reaction vial was placed in a pre-heated $100{ }^{\circ} \mathrm{C}$ oven for 5 days. Plate-like colorless crystals were collected via vacuum filtration and washed with DMF. The product yield based on $\mathrm{Bi}$ is $\sim 77.1 \%$. This reaction was also scaled up with similar yields by doubling reactant quantities in $3 \mathrm{~mL}$ of DMF. Decreasing the quantity of benzoic acid slightly improves the reaction yield and results in smaller particle sizes. When $\mathrm{Bi}\left(\mathrm{NO}_{3}\right)_{2}$ or $\mathrm{BiPh}_{3}$ were used directly in place of the cluster as the metal source, mixed phases and different products were obtained, respectively. 


\section{S3: Single Crystal X-ray Crystallography}

Table S1. Crystal data and structure refinement for 1 (LMOF-401).

Identification code

Empirical formula

Formula weight

Temperature

Wavelength

Crystal system

Space group

Unit cell dimensions

Volume

Z

Density (calculated)

Absorption coefficient

$\mathrm{F}(000)$

Crystal size

Theta range for data collection

Index ranges

Reflections collected

Independent reflections

Completeness to theta $=27.706^{\circ}$

Absorption correction

Max. and min. transmission

Refinement method

Data / restraints / parameters

Goodness-of-fit on $\mathrm{F}^{2}$

Final $\mathrm{R}$ indices [I $>2 \operatorname{sigma}(\mathrm{I})]$

$\mathrm{R}$ indices (all data)

Extinction coefficient

Largest diff. peak and hole
BiK-tcbpe

C60 H46 Bi K N2 O10

1203.07

100(2) K

$0.7749 \AA$

Monoclinic

$\mathrm{C} 2 / \mathrm{c}$

$a=32.0791(13) \AA \quad \alpha=90^{\circ}$

$b=11.9048(5) \AA$

$\beta=99.269(2)^{\circ}$

$c=37.7384(15) \AA$

$\gamma=90^{\circ}$
14223.9(10) $\AA^{3}$

8

$1.124 \mathrm{Mg} / \mathrm{m}^{3}$

$2.793 \mathrm{~mm}^{-1}$

4816

$0.080 \times 0.070 \times 0.015 \mathrm{~mm}^{3}$

2.112 to $27.898^{\circ}$.

$-38<=\mathrm{h}<=38,-14<=\mathrm{k}<=14,-45<=\mathrm{l}<=45$

60475

$13085[\mathrm{R}(\mathrm{int})=0.0804]$

$100.0 \%$

Semi-empirical from equivalents

0.959 and 0.784

Full-matrix least-squares on $\mathrm{F}^{2}$

13085 / 77 / 665

1.023

$\mathrm{R} 1=0.0465, \mathrm{wR} 2=0.1112$

$\mathrm{R} 1=0.0628, \mathrm{wR} 2=0.1168$

$\mathrm{n} / \mathrm{a}$

1.507 and -2.714 e. $\AA^{-3}$ 


\section{S4: Structure Plots and Polyhedral Net Depictions}

a)
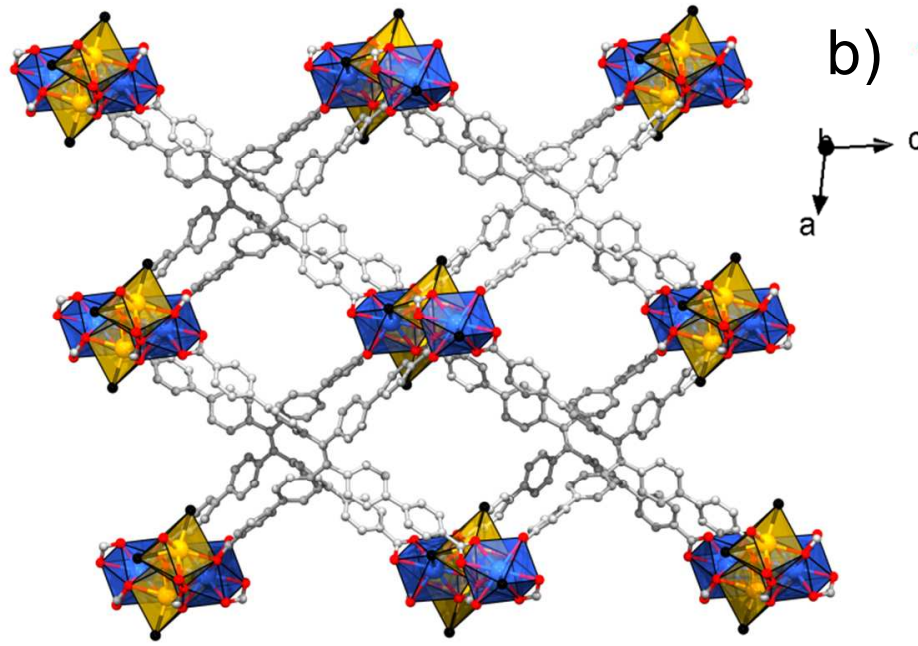

b)
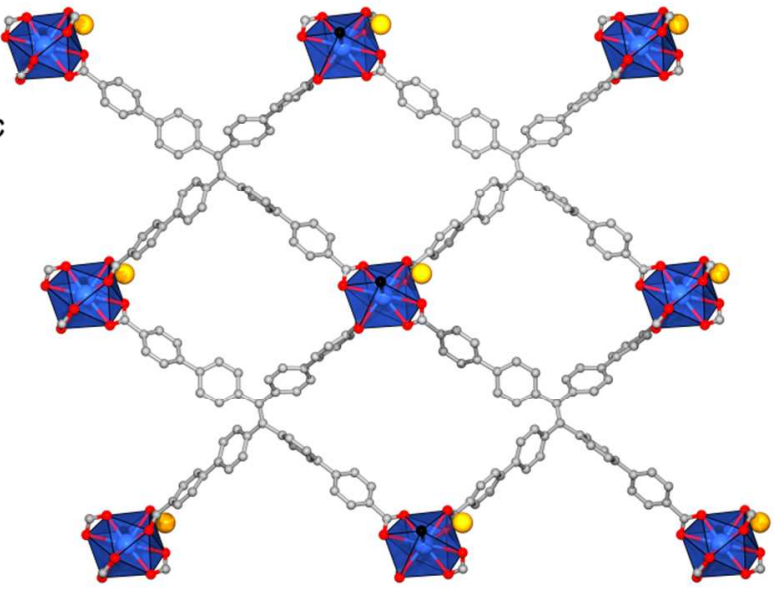

d)
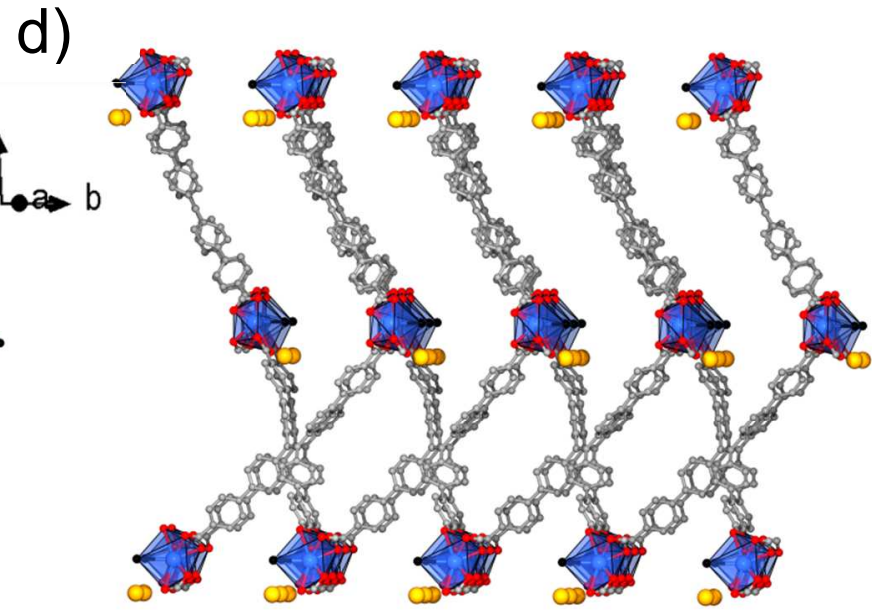

e)

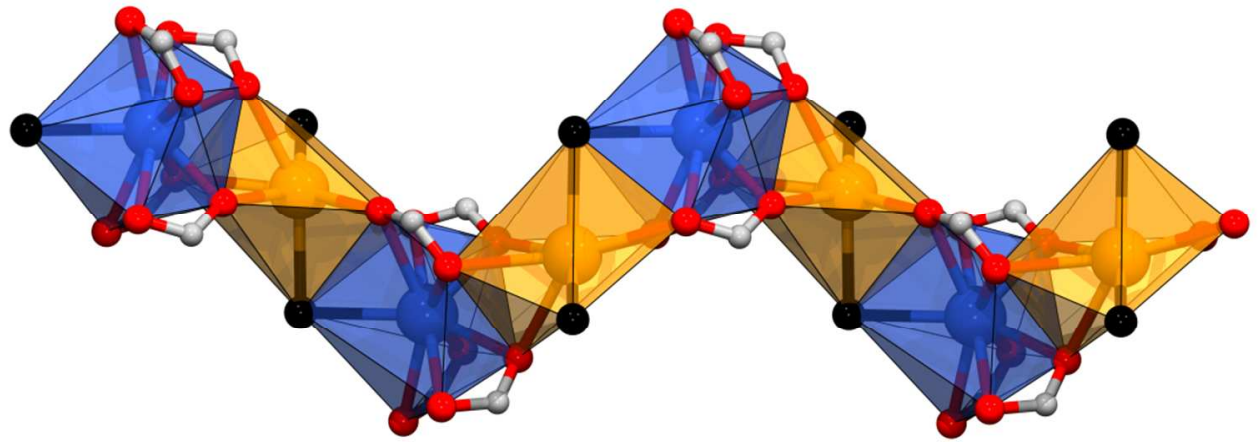

Figure S1. Structure plots of 1 along the $b$-axis $(\mathrm{a}, \mathrm{b})$ and a slightly $a$-axis $(\mathrm{c}, \mathrm{d})$; b) and d) show the connectivity of a single Bi-tcbpe net with potassium bonds removed. e) Close-up view of the inorganic $\mathrm{Bi}-\mathrm{K}$ chain formed through $\mathrm{u}_{3}-\mathrm{O}$ carboxylate and DMF oxygens (red and black spheres, respectively). 
a)

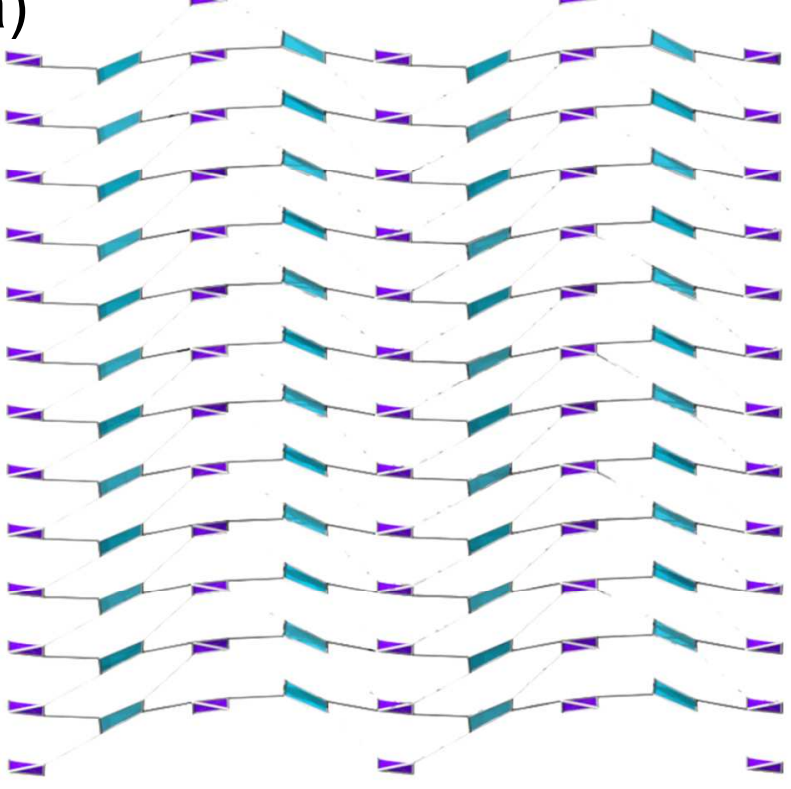

C)

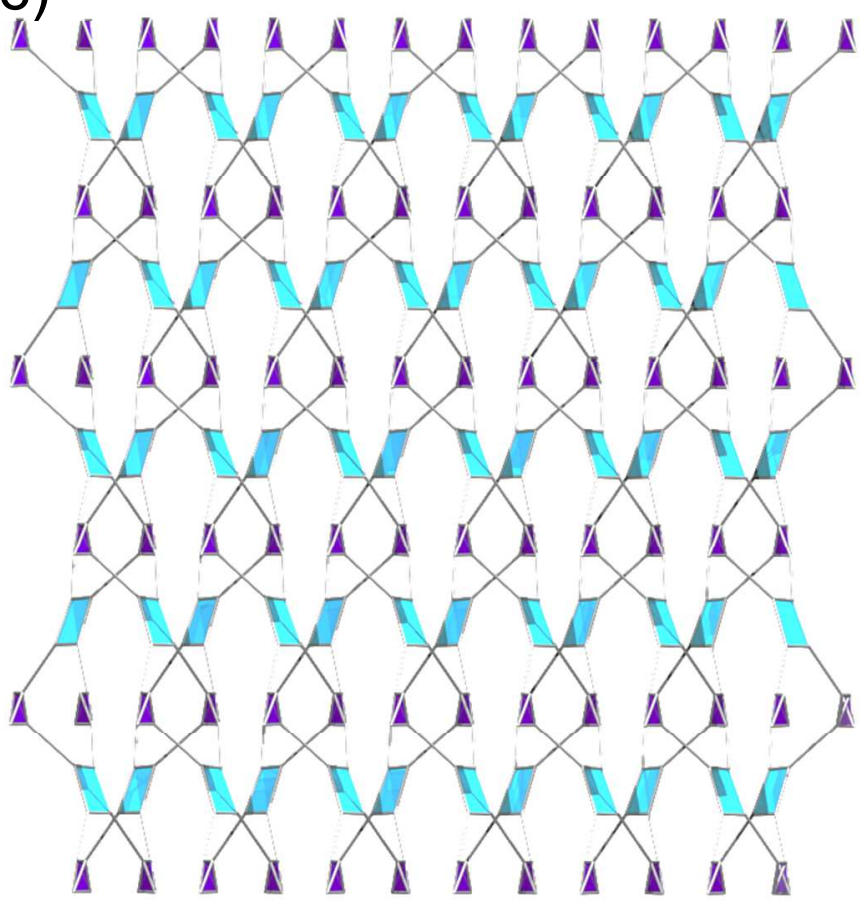

b)

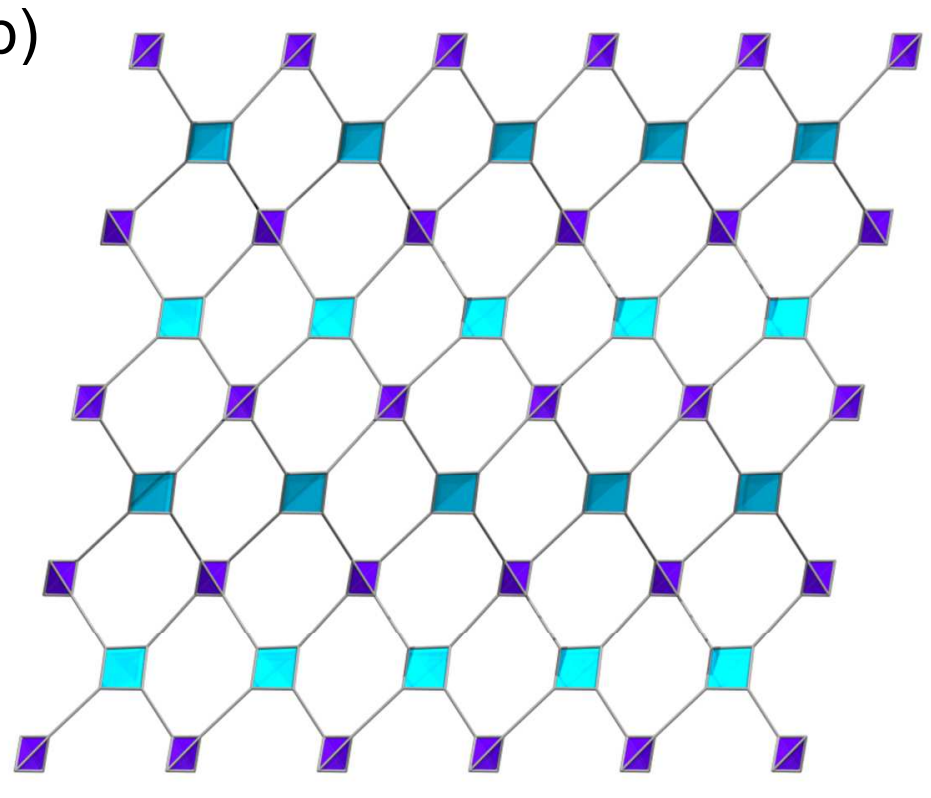

d)

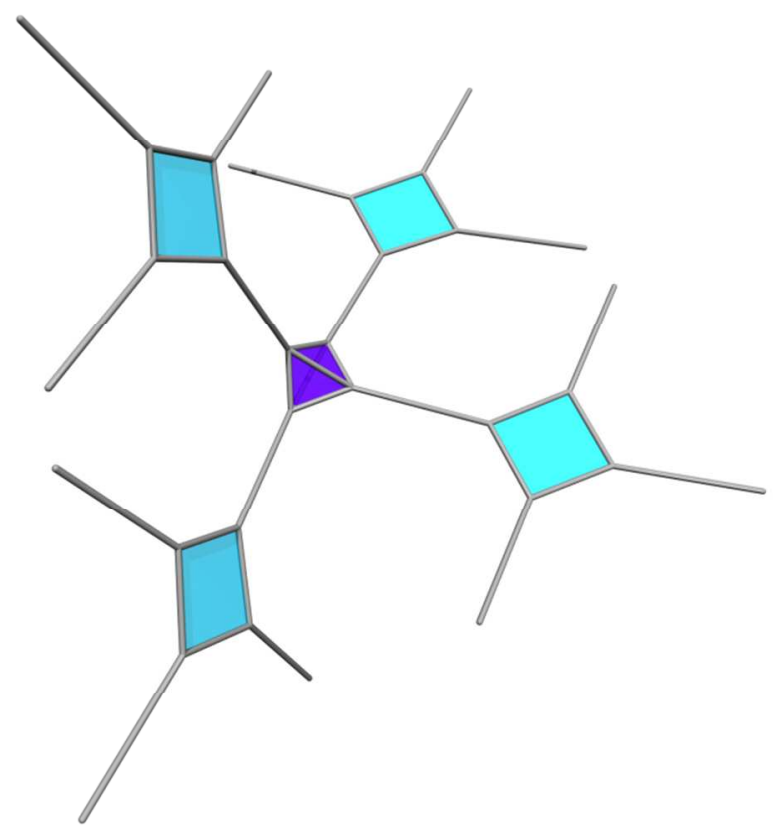

Figure S2. Polyhedral representation of the individual Bi-tcbpe nets in $\mathbf{1}$ as viewed along the crystallographic $a, b$ and $c$ axes (a, b, and c, respectively). d) Connectivity of the highly distorted tetrahedral and rectangular building units. 


\section{S5: Activation Procedure and Solvochromic Studies for the Transformation of 1 to $1 \mathrm{~A}$ and PC-WLED Coating}

The solvochromic properties of 1 were studied through incremental desolvation with corresponding TGA, PXRD and optical measurements. The TGA weight loss from $\sim 50-160{ }^{\circ} \mathrm{C}$ was used to calculate the average DMF content per formula unit, including coordinated DMF. The $\sim 5 \%$ weight loss observed in the TGA profiles after $170{ }^{\circ} \mathrm{C}$ is attributed to ligand degradation, and is also observed in the TGA profile of the pure $\mathrm{H}_{4}$ tcbpe ligand. We describe here the exact methods used to obtain the varying degrees of desolvation.

As-made samples were kept in a vial with a small tissue damp with DMF to prevent drying and chromic shifts; TGA shows an approximate DMF content of 5.3 with a $26.7 \%$ weight loss at this state. By allowing the sample to sit in open-air for less than one hour, the DMF content decreases to $\sim 5.1$. After continued exposure to ambient lab conditions, the DMF content reduces to $\sim 3.7$ and $\sim 3.1$ after 20 and 40 hours, respectively. To obtain additional states of desolvation, samples of 1 were heated to $90{ }^{\circ} \mathrm{C}$ for varying times using the isotherm function of the TGA. Following each heating period, a full TGA measurement was made to establish the remaining DMF content. Specifically, heating $2 \mathrm{mg}$ samples of 1 using this method for 13, 20, 24, 27, 34, and 800 minutes result in approximate DMF contents of $2.3,1.8,1.5,1.1,0.9$, and 0.3 , respectively. To fully activate the sample (denoted as $\mathbf{1 A}$ in the manuscript), $\mathbf{1}$ was simply placed on a watch glass in a $90{ }^{\circ} \mathrm{C}$ oven for five days, at the end of which point the estimated DMF content is 0.0.

$\mathbf{1}$ can also be activated to $\mathbf{1 A}$ through solvent exchange and removal of volatile solvents (Figure S5). After soaking samples of 1 overnight in acetone, dichloromethane, ethanol, methanol, and acetonitrile, the solvents were decanted and the powder allowed to dry. The TGA profile for the $\mathrm{CH}_{2} \mathrm{Cl}_{2}$ is the same as for the 5 day $90{ }^{\circ} \mathrm{C}$ treated sample, and the PL QY was as high as $76 \%$ at $455 \mathrm{~nm}$ excitation. This also suggests that the effect of heating $\mathbf{1 A}$ for 5 days at $90{ }^{\circ} \mathrm{C}$ on PL QY is minimal (74\%@455 nm).

1 was immersed in $\mathrm{H}_{2} \mathrm{O}$ overnight, which results in instantaneous transformation to yellow emission (69\%@455 nm QY), but the PXRD pattern is lacking the two characteristic peaks of 1 A.

\section{PC-WLED Coating}

$\sim 10 \mathrm{mg}$ of $\mathbf{1 A}$ was gently ground in a mortar and pestle and added to a scintillation vial. $0.5 \mathrm{~mL}$ of $\mathrm{CH}_{2} \mathrm{Cl}_{2}$ was added and the slurry was sonicated for two minutes. The suspension was dropcast onto the surface of the LED and was allowed to dry in between coatings. The $10 \mathrm{~W} 450-455$ $\mathrm{nm}$ LED chip was powered by a $12 \mathrm{~V}$ DC power supply at a bias of $\sim 9 \mathrm{~V}$. 


\section{S6: Thermogravimetric Analysis}

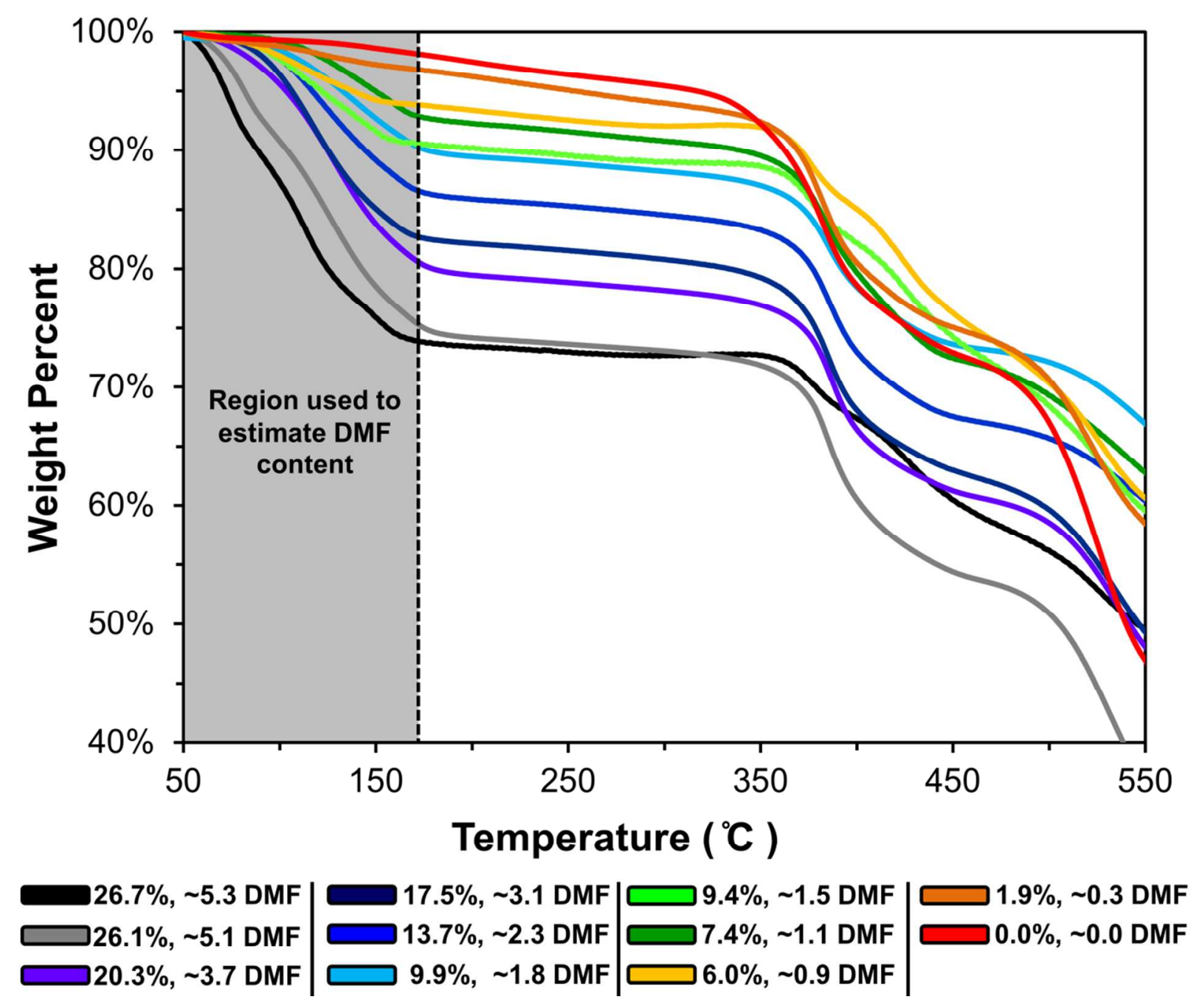

Figure S3. TGA profile for samples of $\mathbf{1}$ at various stages of desolvation. The colored legend at the bottom lists the weight loss in the grey region for each trace, and the corresponding number of calculated DMF molecules per formula unit (including the two coordinated DMF). 


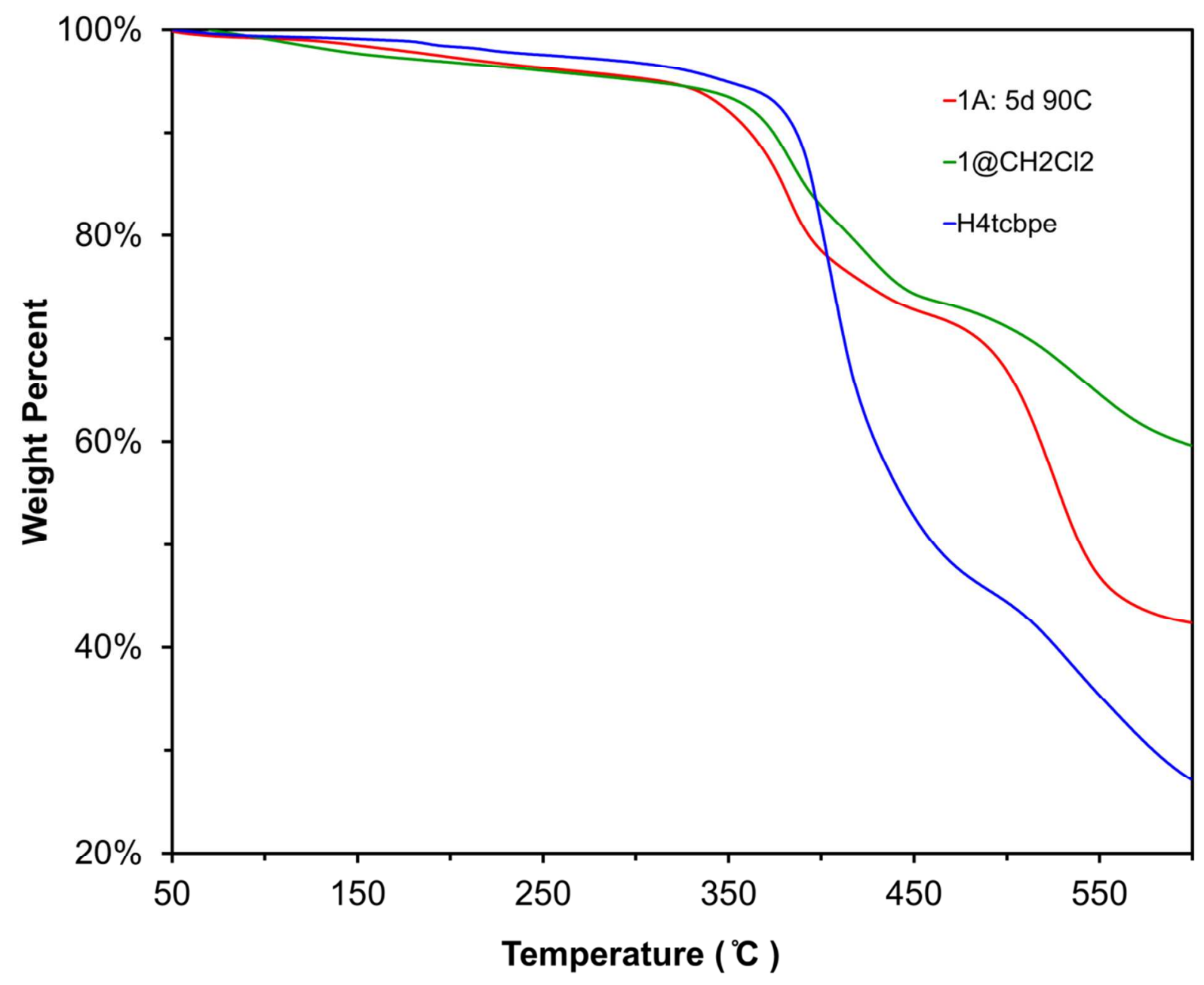

Figure S4. TGA profile for samples of $\mathbf{1 A}$ (red), $\mathbf{1} @ \mathrm{CH}_{2} \mathrm{Cl}_{2}$ (air dried, green), and $\mathrm{H}_{4}$ tcbpe (blue). 


\section{S7: Powder X-ray Diffraction}

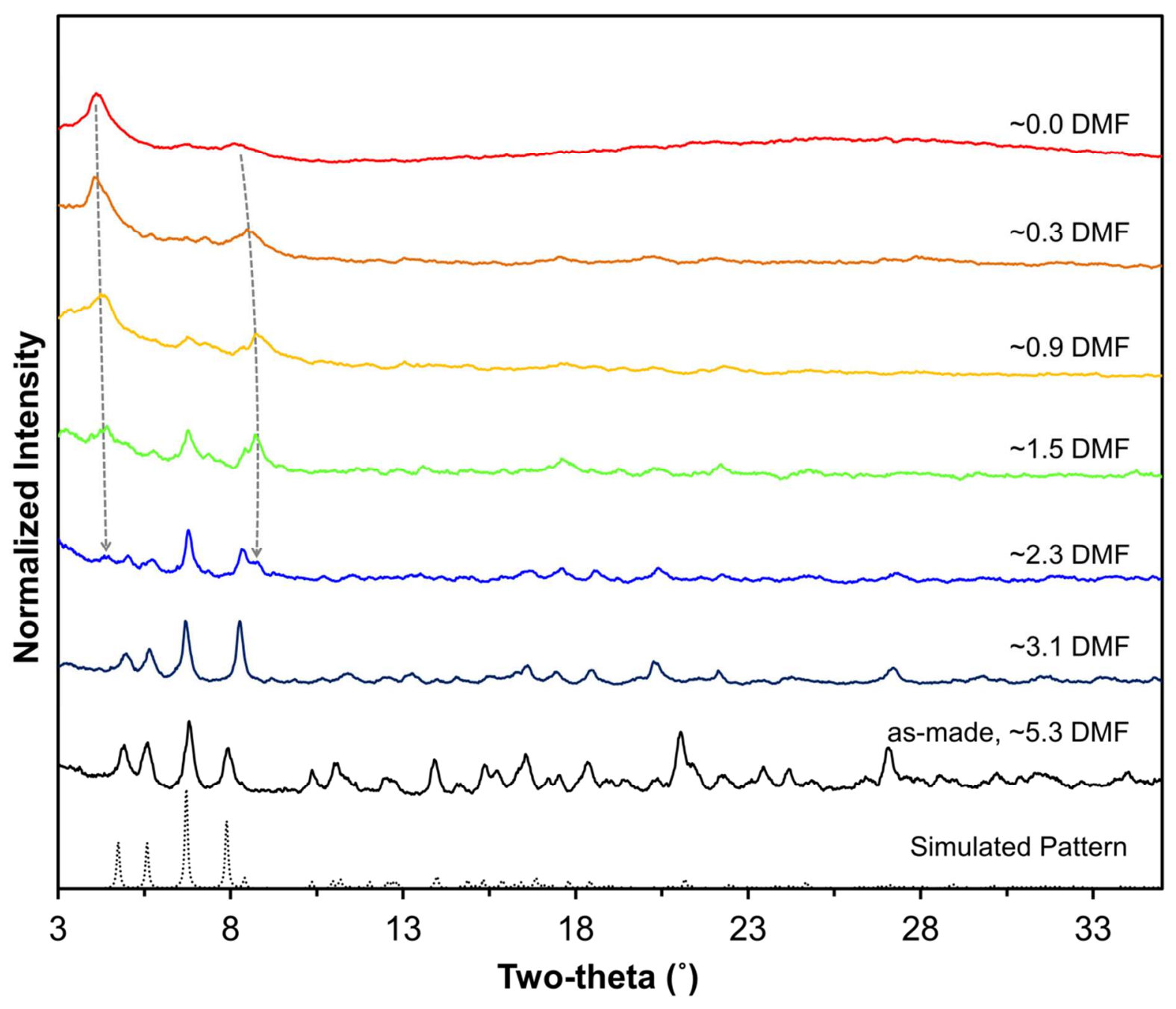

Figure S5. PXRD patterns for 1 during various stages of desolvation. The grey arrows mark the appearance and growth of the peaks corresponding to the activated phase. 


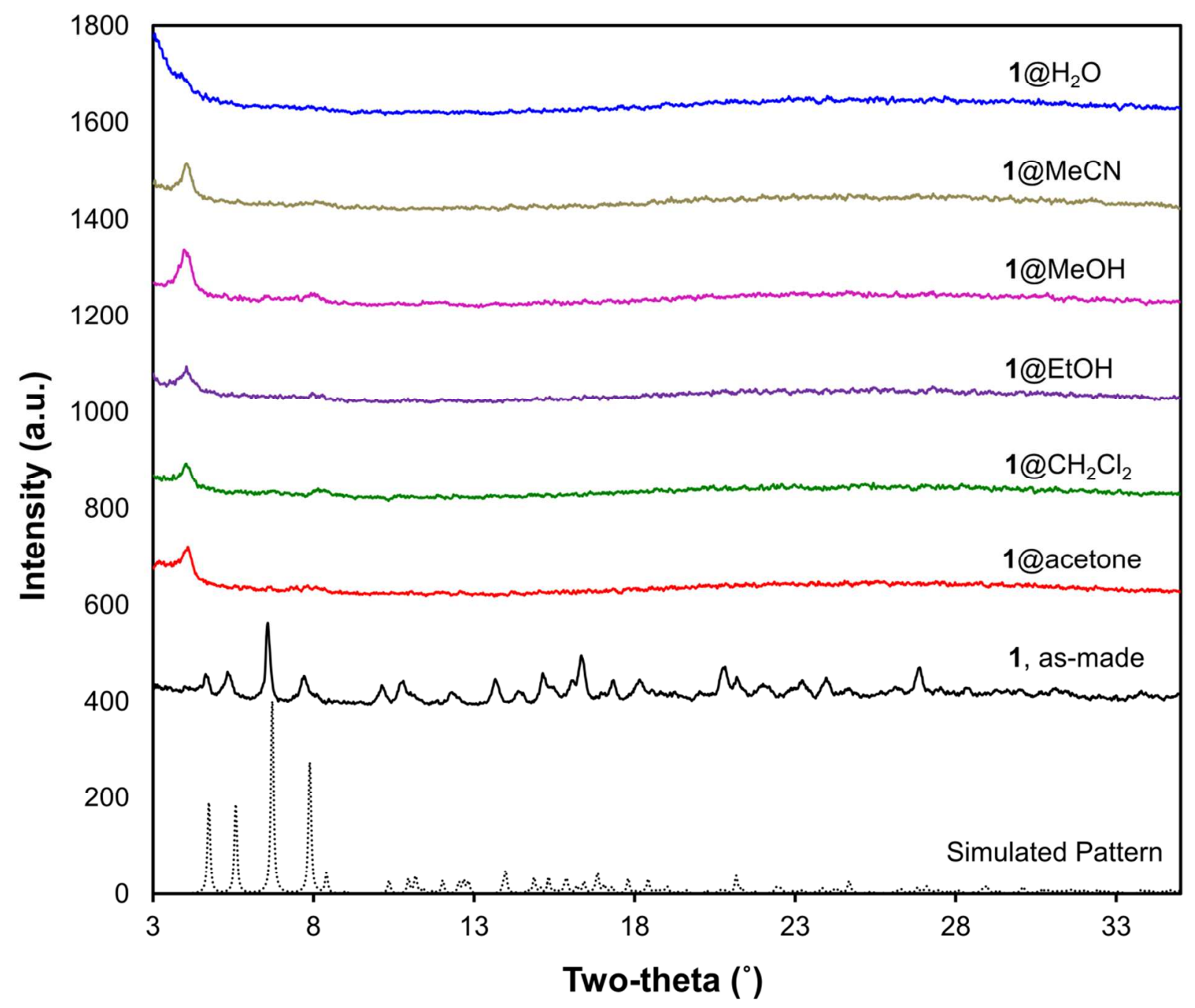

Figure S6. PXRD patterns for $\mathbf{1}$ after solvent exchange with various solvents and air-drying. 


\section{S8: UV-Vis Spectroscopy}

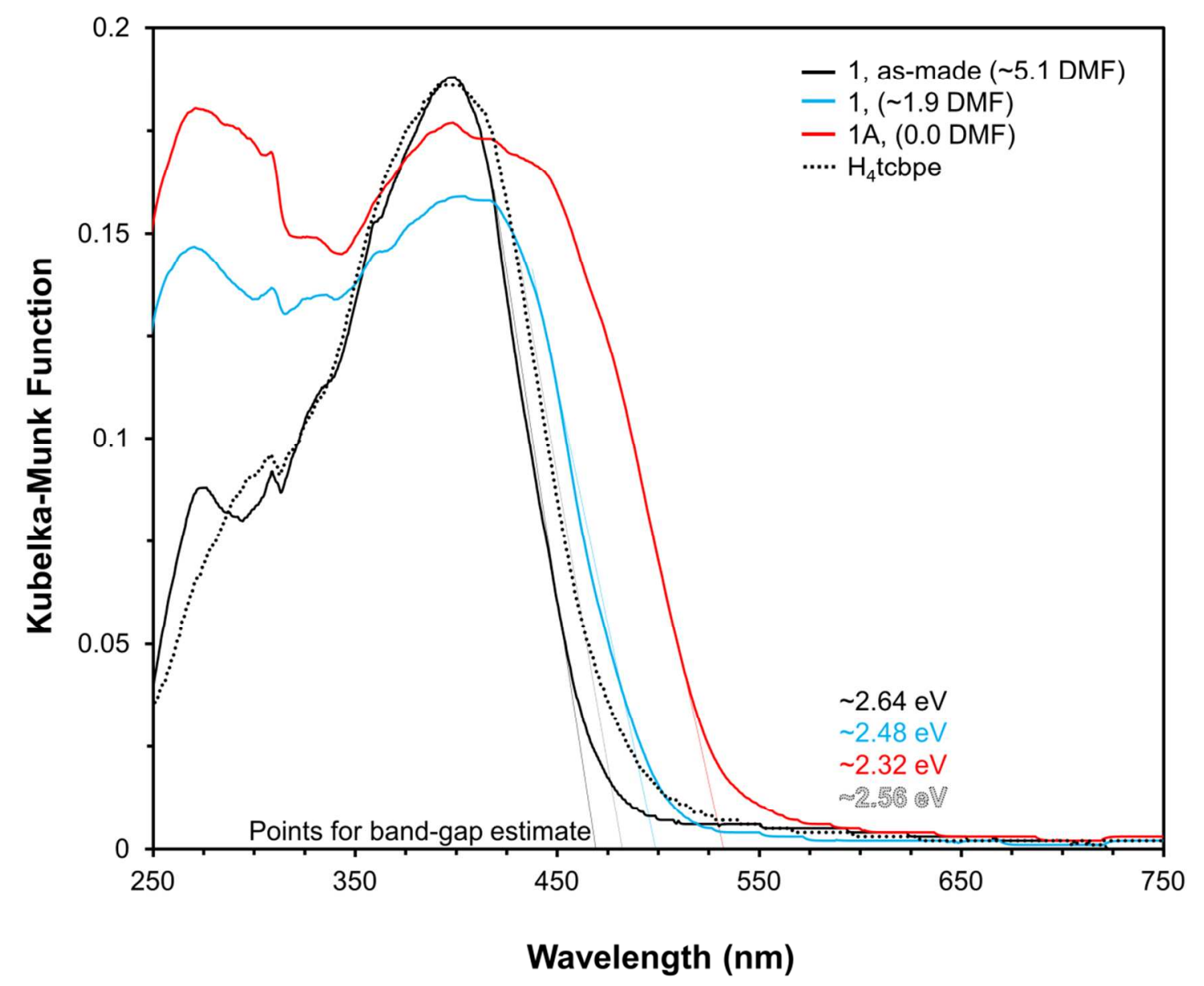

Figure S7. UV-Vis spectra of $\mathbf{1}$ (black), partially desolvated $\mathbf{1}$ (sky blue), $\mathbf{1 A}$ (red), and $\mathrm{H}_{4}$ tcbpe (dotted black). Corresponding lines were added to show the positions used to estimate the optical band gap, which are listed in the bottom right. 

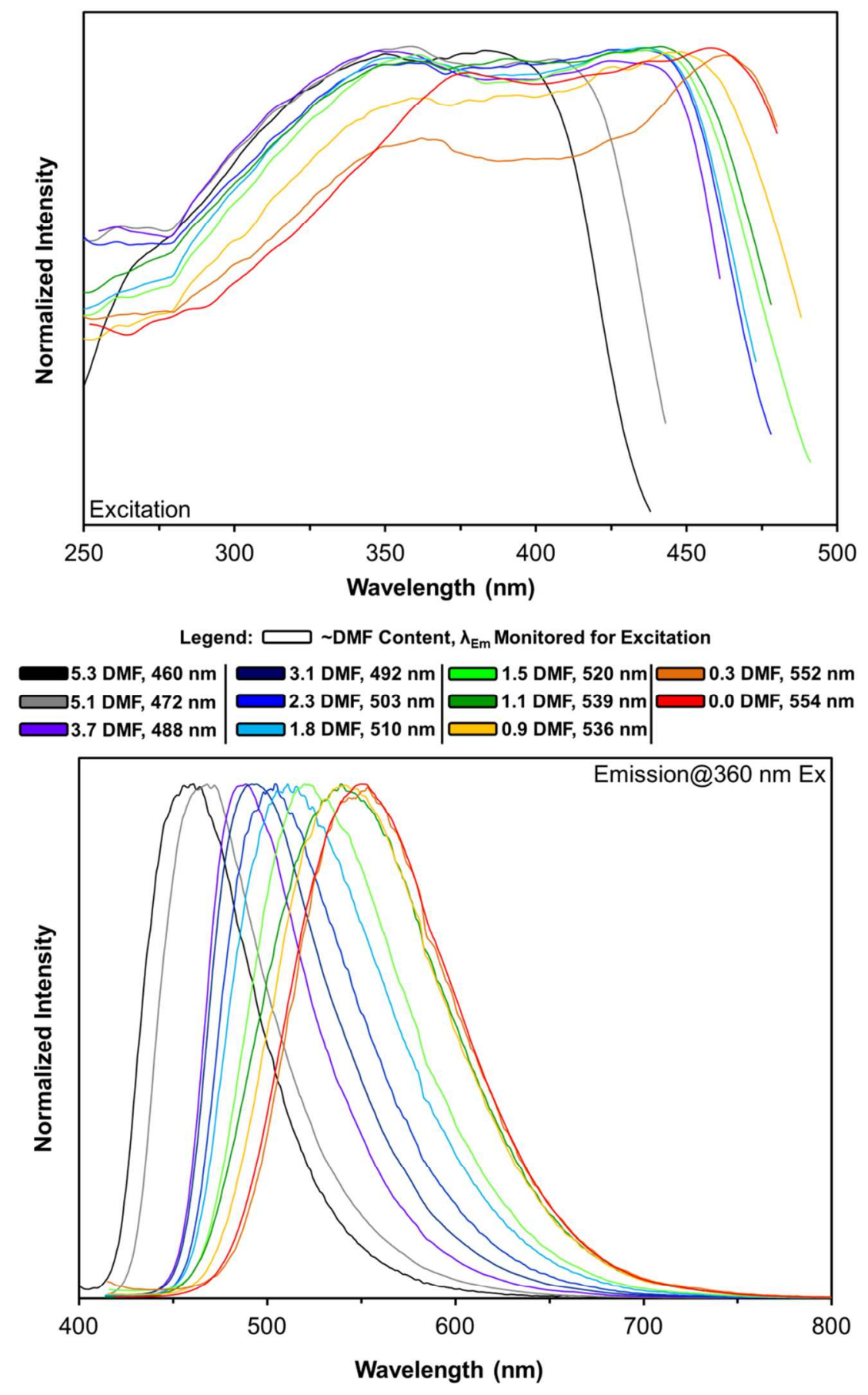

Figure S8. PL excitation (top) and emission (bottom) spectra for $\mathbf{1}$ at various stages of desolvation. The colored legend lists the approximate DMF content per formula unit, and the emission maximum wavelength $\left(\lambda_{\mathrm{ex}}=360 \mathrm{~nm}\right.$ ) used for monitoring during excitation measurements.

\section{S10: Quantum Yield Results}


Table S2: Quantum yield (QY) values obtained at different excitation energies.

\begin{tabular}{|c|c|c|c|c|c|}
\hline Sample & $\begin{array}{c}\text { QY@360 nm } \\
( \pm 0.3 \%)\end{array}$ & $\lambda_{\max }(\mathrm{nm})$ & $\begin{array}{c}\text { QY@455 nm } \\
( \pm 0.3 \%)\end{array}$ & $\lambda_{\max }(\mathrm{nm})$ & $\begin{array}{l}\text { Activation } \\
\text { Procedure }\end{array}$ \\
\hline 1, as-made ( 5.1 DMF) & 57.7 & 462 & - & - & \\
\hline $\mathbf{1 A}$ & 71.5 & 544 & 74.3 & 554 & $5 \mathrm{~d}$ at $90^{\circ} \mathrm{C}$ \\
\hline 1@acetone & 63.6 & 539 & 71.9 & 548 & \\
\hline $1 @ \mathrm{CH}_{2} \mathrm{Cl}_{2}$ & 63.6 & 537 & 76.0 & 546 & \\
\hline $1 @ \mathrm{H}_{2} \mathrm{O}$ & 59.4 & 539 & 69.4 & 555 & \\
\hline $\mathrm{H}_{4}$ tcbpe (as-made) & - & - & 62.3 & 556 & \\
\hline
\end{tabular}

\section{S11: Comparison of Blue-Excitable Yellow Phosphors}

\begin{tabular}{|l|c|c|c|}
\hline Compound & Internal QY (\%) & $\lambda_{\max }(\mathbf{n m})$ & \multicolumn{2}{|c|}{ Reference } \\
\hline $\mathrm{Y}_{3} \mathrm{Al}_{5} \mathrm{O}_{12}: \mathrm{Ce}^{3+}$ & $95 \%$ & 555 & \multicolumn{2}{|c|}{} \\
$(Y A G: C e 3+)$ & & & 1 \\
\hline $\mathrm{Zn}_{2}(\mathrm{tcbpe}) \cdot \mathrm{xDMA}$ & $76.4(455 \mathrm{~nm})$ & 550 & 1 \\
\hline
\end{tabular}

Table S3: Examples of blue-excitable yellow phosphors with high QYs.

*All compounds are excited at $450 \mathrm{~nm}$ unless otherwise stated. 


\begin{tabular}{|c|c|c|c|}
\hline$(L M O F-231)$ & & & \\
\hline $\begin{array}{l}\mathrm{K}\left[\mathrm{Bi}(\mathrm{tcbpe})(\mathrm{DMF})_{2}\right] \cdot x \mathrm{DMF} \\
(L M O F-401)\end{array}$ & $74.3(455 \mathrm{~nm})$ & 554 & This work \\
\hline $\begin{array}{l}{\left[\mathrm{Zn}_{6}(\mathrm{btc})_{4}(\mathrm{tppe})_{2}(\mathrm{DMA})_{2}\right]} \\
(L M O F-251)\end{array}$ & 63.9 & 550 & 4 \\
\hline$\left(\mathrm{Gd}_{\gamma} \mathrm{Y}_{0.999-\gamma} \mathrm{Ce}_{0.001}\right)_{3} \mathrm{Al}_{5} \mathrm{O}_{12}$ & 85 & $530-565$ & 5 \\
\hline $\mathrm{Lu}_{3} \mathrm{MgAl}_{3} \mathrm{SiO}_{12}: \mathrm{Ce}^{3+}$ & 83.4 & 575 & 6 \\
\hline $\mathrm{Lu}_{3} \mathrm{MgAl}_{3} \mathrm{SiO}_{12}: \mathrm{xCe}^{3+}$ & 81.2 & 560 & 7 \\
\hline $\mathrm{Y}_{3} \mathrm{Al}_{3} \mathrm{MgSiO}_{12}: \mathrm{Ce}^{3+}$ & $50 \%$ of $\mathrm{YAG}: \mathrm{Ce}^{3+}$ & 549 & 8 \\
\hline $\mathrm{Y}_{3} \mathrm{Al}_{3} \mathrm{MgGeO}_{12}: \mathrm{Ce}^{3+}$ & $20 \%$ of YAG: $\mathrm{Ce}^{3+}$ & 540 & 8 \\
\hline $\mathrm{Lu}_{2} \mathrm{YMgAl}_{3} \mathrm{SiO}_{12}: \mathrm{Ce}^{3+}$ & 68.6 & 588 & 6 \\
\hline $\mathrm{LuY}_{2} \mathrm{MgAl}_{3} \mathrm{SiO}_{12}: \mathrm{Ce}^{3+}$ & 61.4 & 594 & 6 \\
\hline $\mathrm{Y}_{3} \mathrm{MgAl}_{3} \mathrm{SiO}_{12}: \mathrm{Ce}^{3+}$ & 48.1 & 597 & 6 \\
\hline
\end{tabular}

\section{S12: References}

(1) Hu, Z.; Huang, G.; Lustig, W. P.; Wang, F.; Wang, H.; Teat, S. J.; Banerjee, D.; Zhang, D.; Li, J. Chem. Commun. 2015, 51, 3045-3048.

(2) Boyd, T. D.; Kumar, I.; Wagner, E. E.; Whitmire, K. H. Chem. Commun. 2014, 50, 35563559.

(3) Bai, X.; Caputo, G.; Hao, Z.; Freitas, V. T.; Zhang, J.; Longo, R. L.; Malta, O. L.; Ferreira, R. A. S.; Pinna, N. Nat. Commun. 2014, 5, 5702.

(4) Gong, Q.; Hu, Z.; Deibert, B. J.; Emge, T. J.; Teat, S. J.; Banerjee, D.; Mussman, B.; Rudd, N. D.; Li, J. J. Am. Chem. Soc. 2014, 136, 16724-16727.

(5) Shotaro, N.; Setsuhisa, T.; Kana, F.; Yasushi, F. IOP Conference Series: Materials Science and Engineering 2011, 18, 102005.

(6) Ji, H.; Wang, L.; Molokeev, M. S.; Hirosaki, N.; Huang, Z.; Xia, Z.; ten Kate, O. M.; Liu, L.; Xie, R. J. Mater. Chem. C 2016, 4, 2359-2366.

(7) Shi, Y.; Zhu, G.; Mikami, M.; Shimomura, Y.; Wang, Y. Dalton Trans. 2015, 44, 17751781.

(8) Shang, M.; Fan, J.; Lian, H.; Zhang, Y.; Geng, D.; Lin, J. Inorg. Chem. 2014, 53, 77487755 . 